\title{
Characterization of Environmental Factors for the Prediction of Leaf Rust of Wheat in Sargodha
}

\author{
Yasir Ali ${ }^{1}$, Shahid Iqbal ${ }^{1}$, Zafar Iqbal ${ }^{1}$, Ghulam Abbas ${ }^{2, *}$, Salman Ahmad, \\ Muhammad Sajid ${ }^{3}$, Waseem Sabir ${ }^{4}$ \\ ${ }^{1}$ Department of Plant Pathology, University College of Agriculture, University of Sargodha, Pakistan \\ ${ }^{2}$ Department of Poultry Science, Riphah College of Veterinary Sciences, Riphah International University Lahore, Pakistan \\ ${ }^{3}$ Department of Anatomy, Riphah College of Veterinary Sciences, Riphah International University Lahore, Pakistan \\ ${ }^{4}$ Wheat Research Institute, Ayyub Agriculture Research Institute (AARI), Faisalabad, Pakistan
}

Copyright $\bigcirc 2017$ by authors, all rights reserved. Authors agree that this article remains permanently open access under the terms of the Creative Commons Attribution License 4.0 International License

\begin{abstract}
Wheat leaf rust (Puccinia recondite f. sp. tritici) is amongst major wheat diseases occurring in all wheat growing areas of Pakistan. Losses due to the infection by $P$. recondite f. sp. Tritici have lowered the wheat production potentially in previous years in Pakistan. This problem can be avoided by incorporating resistance against disease in wheat. In the present study eight genotypes/lines were screened and correlated with epidemiological factors i.e. temperature, relative humidity, rainfall and wind speed. The overall results revealed that among all these lines, four genotypes/lines i.e. A-24, A-20, K-11 and A-25 were susceptible to leaf rust of wheat, while the rest of four lines/genotypes i.e. A-09, A-17, A-08 and A-29 were moderately susceptible to this disease. No line/genotype showed resistant, moderately resistant or immune response to leaf rust of wheat. Correlation showed clear response of disease development to environmental factors. Maximum temperature of the disease severity was $23.8-27.15^{\circ} \mathrm{C}$. Similarly, the range of minimum temperature at which disease severity recorded maximum was $16-18^{\circ} \mathrm{C}$. The ranges of relative humidity, rainfall and wind speed on which disease severity was maximum were $60-64 \%, 8-22.50 \mathrm{~mm}$ and $11.8-12.98 \mathrm{Km} / \mathrm{h}$, respectively. The study showed that environmental conditions of Sargodha significantly affected disease development of leaf rust of wheat.
\end{abstract}

Keywords Wheat, Puccinia recondita, Epidemiological Factors, Genotypes, Sargodha, Pakistan

\section{Introduction}

Wheat (Triticum aestivum) is one of the world widely grown life supporting food crops which is consumed in various forms by more than 1000 million people over 60 countries. Wheat (Triticum aestivum L.) is a chief food cereal crop of Pakistan [3]. According to an estimate wheat fulfilled the $50 \%$ requirement of protein and calories on worldwide. It is believed that increase in the production brings about more epidemics to the crop. So the biotic resistance plays an important role in improving wheat production.

Production losses of wheat (Triticum aestivum) have been reported as a result of cereal rust diseases. In Asia (Pakistan \&India), the chronic epidemics of the wheat rust was reported in early 1800 . It was reported that due to the leaf rust $50 \%$ yield reduction of wheat during normal years of wheat production [5]. It is considered that the rust diseases are responsible for the dangerous yield losses and its cyclic revolution is also deliberated as a major factor blamable for the famine in the most part of the world.

Rusts of wheat interrupt the main mechanism of the carbohydrates synthesis. It is considered that the leaf rust of wheat (Pucciniareconditae f. sp. tritici) is a most famous among all rust which has its great effect on the production of wheat. It was reported that up to $10 \%$ wheat yield was reduced due to the leaf rust epidemics of the 1978 [2].

Therefore, to sustain the earnings of the formers and wheat productivity, the suitable approaches and measures should be kept to overcome these serious losses of wheat yield. There are different management approaches used to overcome rust diseases, which are, resistant cultivars, application of fungicides, the chemotherapy of leaf rust is not being used in Pakistan on marketable basis because of low market price of wheat, the health susceptibility fears and the lack of a systematic disease diagnostic pattern.

To escape the rust occurrence there is need to find those varieties which have resistant sources against leaf rust; most fit for growing wheat in diseased areas of any country. It is considered that screening method would be helpful for the future studies on the identification of resistant sources in wheat against the leaf rust. Therefore, the objective of the current study was to characterize the environmental factors for the prediction of leaf rust of wheat in Sargodha. 


\section{Materials and Methods}

\section{Establishment of Screening Nursery}

For the screening of the wheat germplasm against the leaf rust, the 8 lines were sown in the experimental area of Plant Pathology, University college of Agriculture, University of Sargodha, in November 21, 2013. Following dimensions of experimental design were maintained.

Plot size $=40$ feet, Space between two plots $=5$ feet, Space between two rows $=10$ feet

Along with each variety or line, a line of highly susceptible wheat rust spreader i.e. Morocco, was sown. To ensure the maximum disease pressure, the artificial inoculation was done by rubbing and spraying with rust inoculum which are described below.

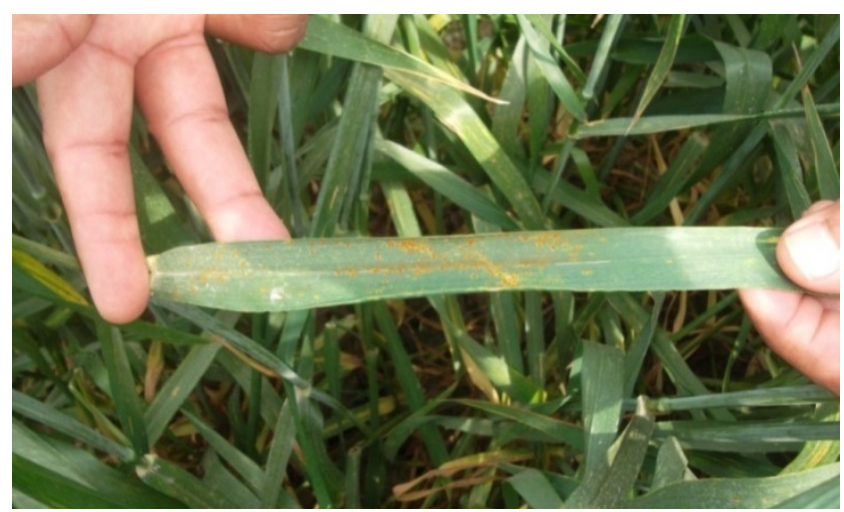

Figure 1. Wheat germplasm showing typical symptoms of leaf rust

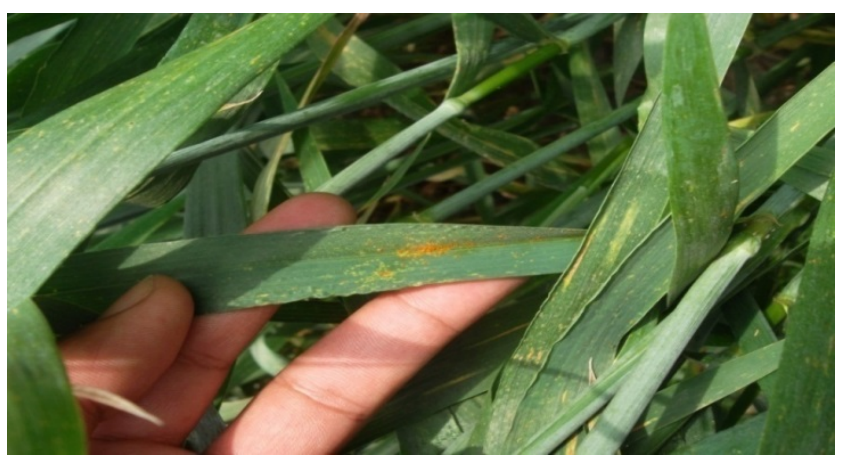

Figure 2. Wheat germplasm showing moderately susceptible reaction against leaf rust

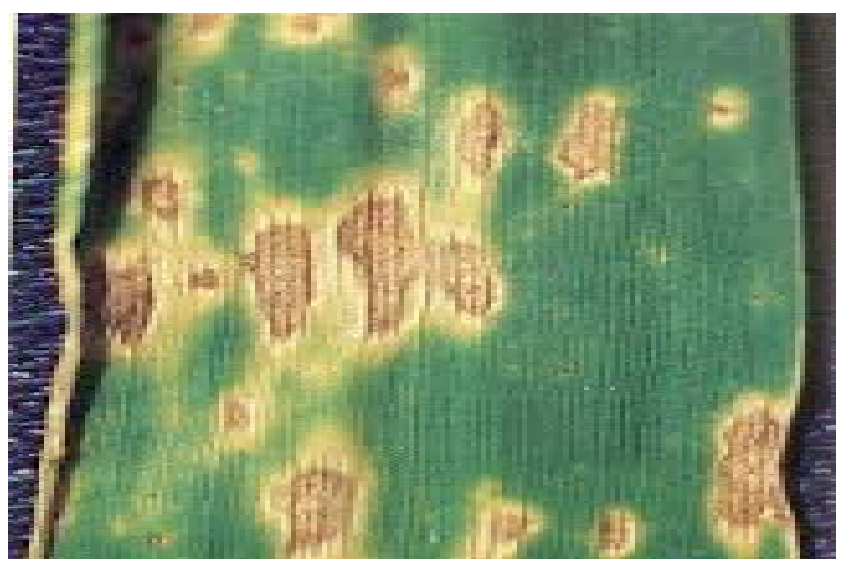

Figure 3. Wheat germplasm showing resistance reaction against leaf rust

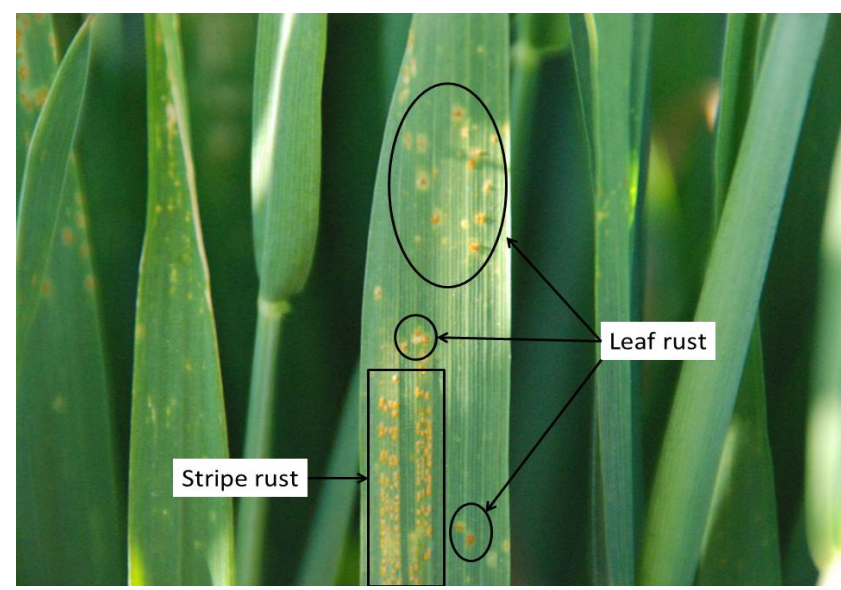

Figure 4. Comparison of leaf rust and stripe rust in wheat germplasm

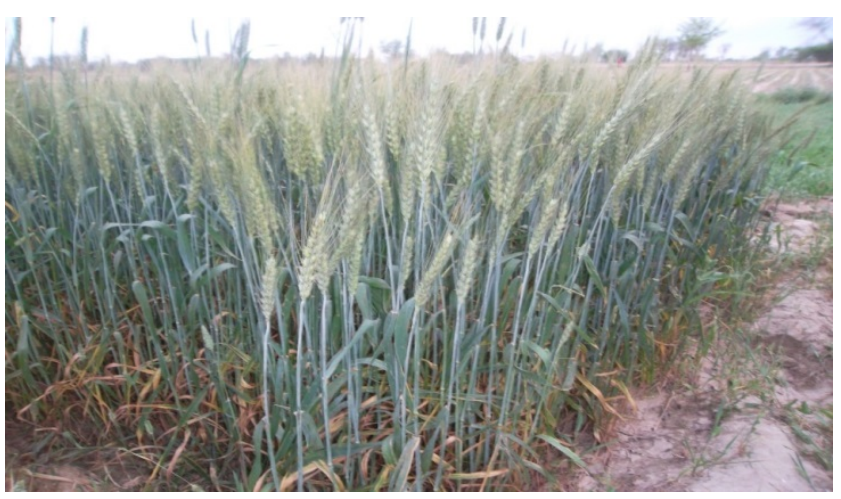

Figure 5. Wheat germplasm under field condition

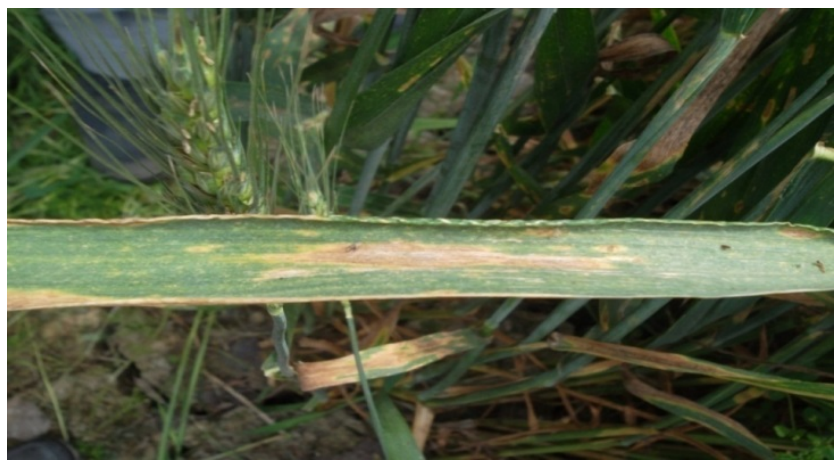

Figure 6. Wheat germplasm showing moderately resistant reaction against leaf rust

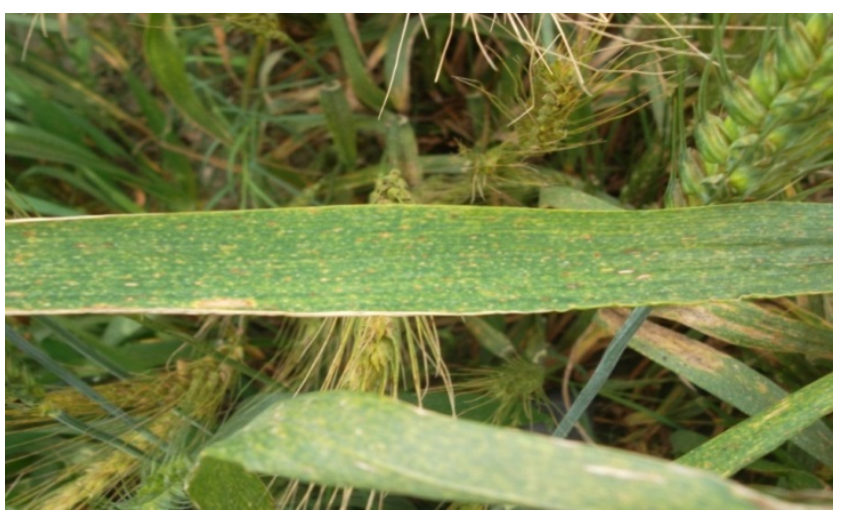

Figure 7. Wheat germplasm showing susceptible reaction against leaf rust 
Table 1. Rust reaction, code for field response and response value

\begin{tabular}{|c|c|c|}
\hline Reaction & Code & Field response \\
\hline No disease & 0 & No visible infection. \\
\hline Resistant & $\mathrm{R}$ & Necrotic areas with or without minute uredia. \\
\hline $\begin{array}{c}\text { Moderately Resistant } \\
\text { Moderately resistant, Moderately } \\
\text { susceptible }\end{array}$ & MR & Small uredia present surrounded by necrotic area. \\
\hline Moderately Susceptible & MS & $\begin{array}{c}\text { The small uredia present surrounded by necrotic areas as well as medium uredia with no } \\
\text { necrosis but possible some distinct chlorosis. }\end{array}$ \\
\hline Moderately Susceptible-Susceptible & MSS & $\begin{array}{c}\text { Medium uredia with no necrosis but possible some distinct chlorosis as well as large uredia } \\
\text { with little or chlorosis present. }\end{array}$ \\
\hline Susceptible & $\mathrm{S}$ & Large uredia and little or no chlorosis present. \\
\hline
\end{tabular}

\section{Recording of Rust Severity}

Leaf rust disease severity and the response of varieties were recorded by the modified Cobb's scale method [4]. The rust data was recorded up to physiological maturity of the wheat. The final disease rating was taken when the spreader attained $80-100 \%$ disease severity. The disease severity on different genotypes were kept recording up to the maturity of crop. Data of environmental conditions i.e. maximum and minimum temperature, relative humidity, rainfall and wind speed were collected from Agro-metrology observatory, University college of Agriculture, University of Sargodha. The relationship between environmental conditions and disease severity were determined through correlation analysis using statistical software. During current research, Minitab 15 by Minitab Inc. U.S.A. were used.

The Cobb's scale was used only to record the severity of rust data.

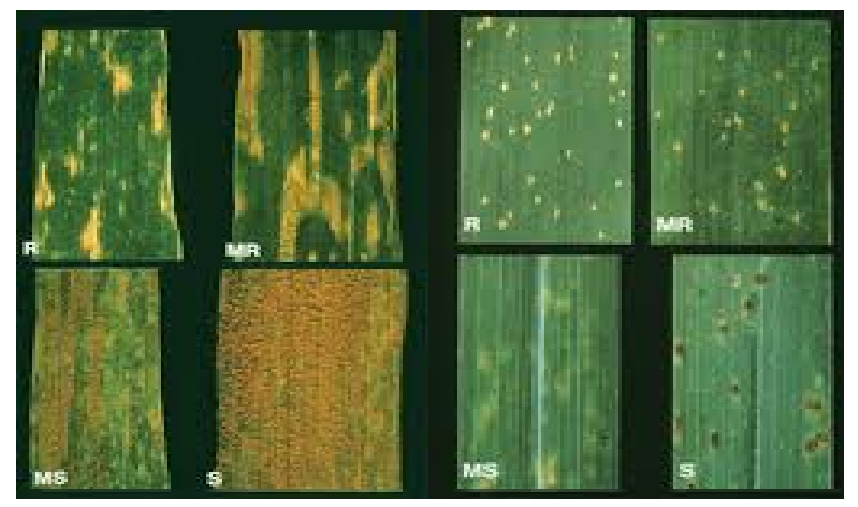

Figure 8. Different leaves which shows different response according to cob's scale method

\section{Relationship of Environmental Conditions Conducive for Leaf Rust Development}

Experimental nursery was planted consisting of eight lines/varieties. Morocco was used as a rust spreader. No fungicides were sprayed to keep the crop under maximum disease severity conditions. In order to maintain crop vigor normal agronomic practices including recommended fertilization dose and irrigation schedule were applied. Data of environmental conditions i.e. wind speed, minimum and maximum temperatures, rainfall and relative humidity was collected from Agro-metrology observatory, University college of Agriculture, University of Sargodha. The relationship between environmental conditions and disease severity was determined through correlation analysis using statistical software. Environmental data served as independent variable while disease severity was used as dependent variable. Environmental parameters having significant influence on brown rust development was studied in detailed by plotting the data graphically. During current research, Minitab 15 by Minitab Inc. U.S.A. was used.

\section{Statistical Analysis}

The environmental data and disease severity data were subjected to correlation and regression analysis to determine the relationship of environment with the disease severity. Data of leaf rust severity recorded on genotypes were processed for AUDPC using CIMMYT AUDPC calculating table.

\section{Screening of Wheat Genotypes/Lines against Leaf Rust}

During the month of March, seven genotypes i.e. A-24, A-20, K-11, A-09, A-17, A-08 and A-29showed moderately susceptible reaction while one i.e. A-25showed moderately resistant reaction. While during the month of April, four varieties i.e. A-24, A-20, K-11 and A-25 were moderately resistant and remaining four i.e. A- $09, \mathrm{~A}-17, \mathrm{~A}-08$ and A-29 were moderately susceptible against leaf rust of wheat.

Eight lines/genotypes were screened out against leaf rust of wheat. Among all these lines, four lines (A-09, A-17, A-08, and A-29) showed susceptible reaction to leaf rust of wheat while rest of four lines/genotypes (A-24, A-20, K-11, and A-25) showed moderately susceptible response to this disease (Table 4). No line/genotype showed resistant, moderately resistant or immune response to leaf rust of wheat (Table 4). 


\section{Response of Different Lines against Leaf Rust on the Base of AULRPC}

Four lines i.e. A-09, A-17, A-08, and A-29 were susceptible with AULRPC value 897.21, 978.86, 950.25, and
1027.21, respectively and the remaining four lines i.e. A-24, A-20, K-11, and A-25 were moderately susceptible with AULRPC value 856.28, 845.64, 895.3 and 857.33, respectively (Table 4).

Table 2. Response of different genotypes/lines against leaf rust of wheat on the basis of AULRPC value during month of March

\begin{tabular}{|c|c|c|c|c|c|}
\hline Reaction & Lines & $\mathbf{1 8 - 0 3 - 2 0 1 4}$ & $\mathbf{2 5 - 0 3 - 2 0 1 4}$ & AULRPC value & \\
\hline 1 & A-24 & 6.67 & 43.33 & 175 & MS \\
\hline 2 & A-20 & 6 & 45 & 178.5 & MS \\
\hline 3 & K-11 & 3.33 & 48.33 & 180.81 & MS \\
\hline 4 & A-09 & 8.33 & 46.6 & 192.26 & MS \\
\hline 5 & A-17 & 7.33 & 66.6 & 258.76 & MS \\
\hline 6 & A-08 & 5 & 50 & 99.15 & MS \\
\hline 7 & A-25 & 3.33 & 25 & 250.81 & MR \\
\hline 8 & A-29 & 18.33 & 53.33 & MS \\
\hline
\end{tabular}

Table 3. Response of different genotypes/lines against leaf rust of wheat

\begin{tabular}{|c|c|c|c|c|c|}
\hline Sr. No. & Lines & $\mathbf{1 - 0 4 - 2 0 1 4}$ & $\mathbf{8 - 0 4 - 2 0 1 4}$ & AULRPC value & Reaction \\
\hline 1 & A-24 & 20 & 13.33 & 116.66 & MR \\
\hline 2 & A-20 & 23.33 & 11.67 & 122.5 & MR \\
\hline 3 & K-11 & 30 & 8.33 & 134.16 & MR \\
\hline 4 & A-09 & 33.33 & 10 & 151.66 & MS \\
\hline 5 & A-17 & 28.33 & 15 & 152 & MS \\
\hline 6 & A-08 & 25 & 16.67 & 145.85 & MS \\
\hline 7 & A-25 & 21.66 & 13.33 & 122.47 & MR \\
\hline 8 & A-29 & 35 & 25 & 210 & MS \\
\hline
\end{tabular}

Table 4. Overall response of different genotypes/lines against leaf rust of wheat on the basis of AULRPC value during year 2014

\begin{tabular}{|c|c|c|c|c|c|c|c|}
\hline Sr. & Lines & $\mathbf{1 8 - 0 3 - 2 0 1 4}$ & $\mathbf{2 5 - 0 3 - 2 0 1 4}$ & $\mathbf{1 - 0 4 - 2 0 1 4}$ & $\mathbf{8 - 0 4 - 2 0 1 4}$ & AULRPC value & Reaction \\
\hline 1 & A-24 & 6.65 & 31.65 & 60 & 55 & 856.28 & MS \\
\hline 2 & A-20 & 5 & 28.33 & 61.65 & 56.65 & 845.64 & MS \\
\hline 3 & K-11 & 7.5 & 31.65 & 65 & 55 & 895.3 & MS \\
\hline 4 & A-09 & 10 & 25 & 66.65 & 63.33 & 898.21 & S \\
\hline 5 & A-17 & 5 & 38.33 & 66.65 & 65 & 979.86 & S \\
\hline 6 & A-08 & 11.5 & 30 & 65 & 70 & 950.25 & S \\
\hline 7 & A-25 & 6.65 & 31.65 & 60 & 55 & 857.33 & MS \\
\hline 8 & A-29 & 8.5 & 40 & 70 & 65 & 1027.25 & S \\
\hline
\end{tabular}

MS=Moderately Susceptible, MR=Moderately Resistant, $\mathrm{R}=$ Resistant, $\mathrm{I}=$ =Immune

Table 5. Correlation of environmental factors with disease severity of leaf rust during year 2014 in Sargodha

\begin{tabular}{|c|c|c|c|c|c|c|}
\hline Sr. No. & Lines & Max. T & Min. $T$ & R.H & Rainfall & Wind speed \\
\hline \multirow{2}{*}{1} & \multirow{2}{*}{ A- 24} & $0.791^{* *}$ & 0.105 & 0.049 & $0.621 *$ & 0.681 \\
\hline & & 0.002 & 0.746 & 0.880 & 0.031 & 0.015 \\
\hline \multirow{2}{*}{2} & \multirow{2}{*}{ A-20 } & $0.765^{* *}$ & 0.068 & 0.076 & $0.627^{*}$ & $0.857^{*}$ \\
\hline & & 0.004 & 0.833 & 0.814 & 0.029 & 0.020 \\
\hline \multirow{2}{*}{3} & \multirow{2}{*}{ K-11 } & $0.870^{* *}$ & -0.004 & 0.165 & $0.767^{* *}$ & $0.776^{* *}$ \\
\hline & & 0.000 & 0.989 & 0.609 & 0.004 & 0.003 \\
\hline \multirow{2}{*}{4} & \multirow{2}{*}{ A-09 } & $0.801 * *$ & -0.057 & 0.205 & $0.738^{* *}$ & $0.744 * *$ \\
\hline & & 0.002 & 0.860 & 0.524 & 0.006 & 0.006 \\
\hline \multirow{2}{*}{5} & \multirow{2}{*}{ A-17 } & $0.841 * *$ & 0.068 & 0.095 & $0.687 * *$ & $0.750 * *$ \\
\hline & & 0.001 & 0.833 & 0.769 & 0.014 & 0.005 \\
\hline \multirow{2}{*}{6} & \multirow{2}{*}{ A- 08} & $0.808^{* *}$ & 0.015 & 0.138 & $0.695^{*}$ & $0.731 * *$ \\
\hline & & 0.001 & 0.963 & 0.669 & 0.012 & 0.007 \\
\hline \multirow{2}{*}{7} & \multirow{2}{*}{ A- 25} & $0.828^{* *}$ & 0.246 & -0.102 & $0.597 *$ & 0.543 \\
\hline & & 0.001 & 0.441 & 0.752 & 0.041 & 0.068 \\
\hline \multirow{2}{*}{8} & \multirow{2}{*}{ A-29 } & $0.861^{*}$ & 0.093 & 0.069 & $0.695 *$ & $0.730^{* *}$ \\
\hline & & 0.000 & 0.773 & 0.831 & 0.012 & 0.007 \\
\hline
\end{tabular}

Upper values indicating Pearson's correlation coefficient; Lower values indicating level of significance at $5 \%$ probability* $=$ Significant $(P<0.05)$; $* *=$ highly significant $(P<0.01)$ 


\section{Correlation of Environmental Factors with Leaf Rust Severity}

All environmental factors i.e. maximum and minimum air temperature, relative humidity, rainfall and wind speed had significant $(P<0.05)$ and highly significant correlation $(P<0.01)$ with leaf rust severity on eight advanced lines (A-08, A-20, K-11, A-25, A-29A-29, A-20, A-17 and A-09) (Table 4).The correlation of Maximum temperature with leaf rust of wheat was statistically significant on four advanced lines i.e. A-29, A-08, A-25, and A-20 while the rest of four advanced lines i.e. K-11, A-20, A-24, and A-17 had statistically highly significant correlation (Table 4). The correlation of minimum temperature and rainfall with leaf rust of wheat was highly significant on all eight advanced lines (Table 5). Only three advanced lines i.e. K-11, A-09, and A-17 had statistically highly significant correlation and the remaining five lines i.e. A-24, A-20, A-08, A-25, and A-29 had statistically significant correlation with relative humidity (Table 5). Five advanced lines/genotypes i.e. A-24, A-20, K-11, A-25, and A-29 had statistically significant correlation while remaining three genotypes or lines i.e. A-09, A-17 and A-08 had statistically highly significant correlation with wind speed (Table 5).

\section{Relationship of Environmental Conditions Conducive for Leaf Rust of Wheat}

\section{Maximum Temperature vs. Leaf Rust Severity}

Different genotypes showed different reaction to maximum temperature (Fig. 1). The relationship of maximum temperature with percentage disease severity of leaf rust on most of the genotypes/lines was positive and it was best explained by the linear regression especially in case of genotypes/lines A-24, A-20, K-11 and A-09.The correlation of maximum temperature with leaf rust was positive. With increase in maximum temperature from 24 to $27.25{ }^{\mathrm{O}} \mathrm{C}$ leaf rust severity increased gradually (Fig. 1). At 27 to $28^{\circ} \mathrm{C}$ the leaf rust severity was maximum . The relationship was best explained by linear regression model as indicated by $0.79,0.76,0.87$ and $0.80 \mathrm{r}$ values, respectively (Fig. 1).

\section{Minimum Temperature vs. Leaf Rust Severity}

The relationship of the minimum temperature with leaf rust was positive. The lines (V-1, V-2, V-3 and V-4) showed non- significant relationship to leaf rust of wheat. With the increase of maximum temperature from 16 to $19^{\circ} \mathrm{C}$ leaf rust severity also increased. This shows clear response of leaf rust values of the lines to minimum temperature. At $16^{\circ} \mathrm{C}$ the disease severity of leaf rust was the minimum. The $\mathrm{r}$ values of A-24, A-20, K-11 and A-09 were 0.05, 0.08, 0.16 and 0.20, respectively.

\section{Rainfall vs. Leaf Rust Severity}

Response of different lines was different to rainfall (Fig.
4). The relationship of rainfall with the percentage of disease severity of leaf rust on most of the lines was positive and it is evident from linear regression in case of lines A-09, A-08, A-17 and A-29. With the increase of rainfall from 8.2 to $22.50 \mathrm{~mm}$, the severity of leaf rust also increased gradually (Fig. 4). The relationship was best explained by linear regression models as indicated by $0.62,0.63,0.77$ and $0.74 \mathrm{r}$ values, respectively.

\section{Relative Humidity vs. Leaf Rust Severity}

Different genotypes responded differently to relative humidity (Fig. 3). The relationship of relative humidity with percent disease severity of leaf rust on most of the genotypes was positive and it was best explained by linear regression in case of genotypes A-29, A-08, A-17 and A-09. With increase in relative humidity from 55 to $64 \%$, leaf rust severity also increased gradually (Fig. 3).Leaf rust disease severity was highest when relative humidity increased from 60 to $64 \%$. The relationship was best explained by linear regression models as indicated by $0.05,0.08,0.16$ and $0.20 \mathrm{r}$ values, respectively.

\section{Wind Speed vs. Leaf Rust Severity}

The relationship of wind speed with the leaf rust was positive. The lines (A-29, A-09, A-17, and A-08) showed significant response to the leaf rust disease severity. With the increase of wind speed from 11.80 to 12.98 the leaf rust also increased. At 12 to $13 \mathrm{Km} / \mathrm{h}$ the disease severity was the maximum. This shows the clear response of leaf rust disease to wind spread.

\section{Discussion}

The fungal diseases cause a potential threat to successful production of wheat particularly in Pakistan. In the all wheat growing areas of the world, the wheat leaf rust (Puccinia reconditae f. sp. tritici) is the major wheat disease and causes enormous losses in the production of wheat. The susceptible cultivars and favorable environmental conditions also give rise to the establishment of fungal diseases. To avoid the wheat and other crop from the infection of rusts, sowing of disease resistant cultivars is the only effective and sustainable solution. The disease can also be controlled by the use of fungi toxicants. Therefore, to analyze the resistant sources there is need of extensive screening of wheat germplasms. Hence, in the current study the effort was made to identify the resistant sources for the wheat germplasm against the leaf rust and their relation to epidemiological factors. For this, the artificial inoculation of wheat advanced lines/germplasm was done by using of various approaches like rubbing, transplantation of rusted plants, spraying and inoculum dusting with talcum powder.

Eight lines were assessed for their response to leaf rust of wheat. The four lines (A-29, A-08, A-17, and A-09) showed susceptible reaction to leaf rust of wheat while remaining 
four lines (A-25, K-11, A-20, and A-24) showed moderately susceptible response to leaf rust disease. No line/genotype showed resistant, moderately resistant or immune response to leaf rust of wheat.

In 2000, Reis et al. [7] used same technique i.e. spraying of urediospores suspension on the wheat genotype to evaluate the resistant source. Including a control (Morocco) after every $9^{\text {th }}$ variety or genotype, the two hundred genotypes were screened against reaction of leaf rust disease severity. Among them, 66 were immune, 48 lines showed durable resistance and 66 were susceptible against leaf rust while 79 were immune.

Arora et al. [1] conducted the same work by screening 158 Aestivum and Durum wheat lines during 1987 and found that only one genotype was immune, four were resistant against the leaf rust. To predict the disease severity, the relationship of environmental conditions or epidemics to the infection behavior of leaf rust has its importance as well.

Hussain et al. [3] studied the occurrence of race 104 Puccinia reconditae $\mathrm{f}$.sp. tritici of which three pathotypes were distinguished. However, the new races were unable to overcome the resistance genes Lr-13 and Lr-26 mostly occurring in cultivars of Pakistan.

The epidemiological factors play an important role for the management of epidemics of leaf rust disease. The study of environmental factors with leaf rust help out to predict the leaf rust epidemics, so that precautionary measures should be taken to minimize the yield losses which occurs due leaf rust disease. In the current study, the focus was to identify the resistant sources and to determine the epidemiological factors favoring the leaf rust. In the study a positive correlation between leaf rust and maximum temperature was observed on all eight genotypes/lines. It was observed that four lines were significantly correlated with temperature and leaf rust disease severity increase with the increase in temperature.

Singh and Tiwari [6] described that the relative humidity ranging from $42.8 \%$ to $88.2 \%$ (an increasing trend) was favorable for the development of leaf rust disease severity. Discussing the epidemics of leaf rust disease severity, wind spread cannot be neglected. Probing out this relationship, a significant correlation was observed between leaf rust disease severity and wind spread.

Vallavieillie et al. [8] observed that under the optimal temperature and non-limiting moisture duration for the infection efficiency was 12 times greater for Puccinia. Reconditae f. sp. tritici than for P. striformis. On the other hand, the penetration of both species was similarly affected by a 1 hour dry period interrupting a 24 hour wet period 1, 2, $4,6,8$ or 16 hours after inoculation at several temperatures between 5 and $30^{\circ} \mathrm{C}$. Appressoria from the germinated Puccinia recondita urediospores before penetration were unable to survive the 1-hour dry period. An interruption of wet period by a dry period did not affect the ungerminated urediospores which were able to infect the leaves during a following dew period.
The minimal continuous dew period necessary for infection increased from 4-6 hour at optimal temperature $\left(15^{\circ} \mathrm{C}\right.$ for Puccinia reconditae, and $8^{\circ} \mathrm{C}$ for $P$, striformis $)$ to at least 16 hour at sub-optimum temperature infection by $P$. recondita f. sp. tritici occurred over a wide range of temperature $\left(5-25^{\circ} \mathrm{C}\right)$. The percentage of the infection as function of duration of the continuous dew periods were described by Richard's function with temperature dependent parameters for a dry period interrupting the 24 hour dew period before the minimum continuous period of dew necessary for infection percentage of infection at the specific temperature was filled by a negative exponential function of time of interruption. If the dry period followed after the least dew period for infection percentage of infection was the same as with continuous damp duration.

\section{Conclusions}

It was concluded that the environmental conditions of Sargodha are favorable for development of leaf rust. However, this disease can easily be controlled by applying excellent management practices and screening is the best way for genetic control of leaf rust of wheat in Sargodha.

\section{REFERENCES}

[1] P. C., Arora, G., Anil, R. S., Basant, A., Singh, M. Gupta, and B. Ram, (1987). Screening of wheat germplasm against brown rust and yellow rust .Ind. J. Mycol. Pl. Pathol., 17: 60-71.

[2] A. Hafiz, (1986). Plant diseases. PARC. Islamabad. pp: 552.

[3] M., Hussain, N., Ayub, S. M. Khan, M. A., Khan, F. Muhammad, and M. Hussain, (2006). Pyramiding rust resistance and high yield in bread wheat. Pak. J. Phytopathol., 18: 11-21.

[4] R. F., Peterson, A. B. Campbell, and A. Hanna, (1948). A diagrammatic scale for estimating rust severity on leaves and stems of cereals. Can. J. Res. Sec. C., 26:496-500.

[5] A. P. Roelf, (1978). Estimated losses caused by rust in small grain cereals in the United States 1918-1076. Misk publ. U. S. Dept. Agric. 1363:1-85.

[6] T. B. Singh, and A. N. Tiwari, (2001). Role of weather conditions in the development of foliar disease of wheat under tarai conditions of north-western India. Pl. Dis. Res., 16:173-178.

[7] E. S., Reis, R. T., Casa, L. L. Hoffman, andC. M. Mendes, (2000). Effect of leaf rust on wheat grain yield. Fitopathologia Brasilieria 25(1):67-71.

P., Vallavieillie, L., Huber, M. Lecente, and H. Goyeav, (1995). Comparative effect of temperature and interrupted wet period on germination and infection of $\mathrm{P}$. reconditae on wheat seedling. Phytopath. 74: 545-548. 